\title{
PLANNING FOR WILD LANDS
}

What would the world be, once bereft

Of wet and of wildness? Let them be left,

$O$ let them be left, wildness and wet;

Long live the weeds and the wildness yet.

Gerard Manley Hopkins (1844-1889)

Recently we read a strong re-statement of the case for wilderness areas in a Canada Department of Forestry pamphlet written by J. S. Rowe and entitled "Nature protection - wilderness and natural areas" (Ottawa, 1962). Mr. Rowe feels that there is little public interest in wilderness and natural areas in Canada as compared to the United States, and that there is less incentive for governmental agencies in Canada to get deeply involved in study of this particular land-use question. This statement reminds us how vital it is for organizations like the Saskatchewan Natural History Society to press for planning for wild lands.

"The planning of land use," concludes Mr. Rowe, "is the most significant type of national planning, for in the long run the health and prosperity of the people depend on it. Man creates his own environment; he can be wasteful and destructive or far-sighted and conserving, he can surround himself with unplanned ugliness or with planned beauty.

"Fortunately in Canada we can afford to preserve Wilderness primitive areas set aside for those forms of recreation founded on appreciation of scenic splendour. But by their very nature, Wildernesses will always be remote from centers of population and will be accessible only to a minority of users. They need to be supplemented by Natural Areas - smaller fragments of the primeval landscape preserved for aesthetic, cultural and scientific value.

"Natural Areas should be established in large numbers across the country, preserving representative samples of native plant and animal communities on typical terrain as well as in uniquely interesting habitats. They will serve many purposes, not least of which may be that of introducing town and city dwellers to the native landscape, nurturing that affection for the land of which conservation and tasteful environmental planning are the ultimate expression."

This philosophy of land-use has been implicit in the efforts of our Society over the years toward the establishing of a grassland park, and we look forward to seeing an example of Mr. Rowe's advocated "natural areas" take shape in the new national park being planned now for the Canadian prairies. In a letter to the Blue Jay Editor Mr. Rowe himself has written warmly of the proposal for a national grassland park: "Years ago I worked for P.F.R.A. out of Swift Current, on the Community Pasture Survey, and recall with pleasure many happy days of rambling through the Great Sand Hills, the Cypress Hills and the unbroken grasslands to the south. It was quite an experience to find large tracts of prairie where one could stand and look in all directions and see no signs of telephone posts or fences; the feeling that a herd of buffalo or antelope might suddenly appear was strong and, indeed, one could still discern faintlv the old buffalo trails leading down to the water holes." 